\title{
Exploration of Crew Resource Management Concept Based on UAV System
}

\section{Z.Q. Ren}

First Department, First Aeronautic Institute of Air Force, china.

\author{
H.F. Cheng, G.L. Huang \\ Flight Instructor Training Base, Air Force Aviation University, china.
}

\begin{abstract}
The introduction of crew resource management idea to optimize the aviation system resources to UAV system, improve the overall ability, and ultimately achieve rapid, accurate, efficient objective. Based on researching the connotation on crew resource management, puts forward the concept of UAV system resource management, expounds the importance of the introduction of crew resource management concept in the UAV system, analyzes the problems facing the management of system resources in the UAV system, gives a few suggestions on crew resource management UAV system.
\end{abstract}

KEYWORD: Unmanned aerial vehicle; System; Crew resource; Management idea

\section{GENERAL INSTRUCTIONS}

Analysis of the causes of the plane crash related data show that, "human factors" account for about $80.5 \%$ of. The unit causes accounted for $62 \%$, accounted for $15 \%$ of operating procedures, repair factors accounted for $3.5 \%$. In view of this, if not solve the problem of man-made factors, it is difficult to fundamentally improve the flight safety situation, this kind of understanding has become a worldwide consensus. Crew resource management (Crew Resource Management, CRM) is defined as the effective use of all available resources (including hardware, software, environment and human resources), to achieve the safe, efficient and comfortable flight purposes, so as to effectively reduce the occurrence of human problems. [1]Therefore, the introduction of crew resource management philosophy to the UAV system, carry out the UAV system resource management, to optimize the system resources, improve the overall ability, and ultimately achieve rapid, accurate, efficient objective.

\section{THE CONCEPT OF CREW RESOURCE MANAGEMENT}

\subsection{The crew resource management implications}

Crew resource management consists of cockpit resource management evolved, refers to the full, effective, reasonable use of all available resources to achieve the purpose of safe and effective flight, the core content is the authority, to participate in, decisions, respect, can effectively improve the crew communication skills, to promote team spirit, assign task, right decision reflection. The research object of crew resource management is the unit and its resource, the objective is safety and efficiency, around this objective management, training content of crew resource management, including flight of man, machine, environment, system in various task factors, human factors based.

\subsection{The UAV system resources}

$U A V$ system resources including the ground control station and the ground control station with each seat control activities related to resources, linked together through the seat control personnel. Summary should include: human resources, equipment resources, information resources and other resources.

\subsection{1 human resources}

Human resources are found in human economic resource, also known as human resources, labor resources, labor resources. The human resources of the production, development, configuration and use and many other aspects of the management by objectives referred to human resource management. The UAV system resource management is to improve the work in the UAV system in people's work ability and work efficiency as the goal, including personnel, control of each subsystem in 
the professional skills, communication skills, individual term and teamwork skills.

\subsubsection{Device resources}

Device resource refers to an aircraft platform, manmachine system in airborne equipment and ground control station, also can become the hardware resources. The design and management of flight of UAV system, the use of high technology, the use of automation system, which makes the cockpit essentially changed control automation system, a lot of shelter changed flight controllers during the flight behavior, equipment resource is the extension of human resources, all kinds of automatic control systems make flying safer and more efficient.

\subsubsection{Information resources}

The information is intended to study the amount of information and news, send, transmit and receive science called information theory. UAV system due to the true feelings of the aircraft's flight state, so that the physical load control personnel is more and more small, and the information processing requirements and psychological load increasing. The control module controls the personnel to develop situational awareness information is obtained, the task information is effective control personnel to plan and make decisions need to be sources of information, including: flight manuals and check lists, aircraft performance manual, chart, integrated information, the target area of meteorological information, ATC radar information, information and task scheduling. Link system the carrier of information, will be all kinds of information transfer between the aircraft platform and the ground control station.

\subsubsection{UAV system resource management}

As a new concept of safety management of manmachine system resource management, it takes the UAV system personnel exchanges, and decisionmaking skills and work assignment as the focus, purpose is through the use of all available resources, maximize the system running efficiency and ensure flight safety. The object of UAV system resource management including software (such as file management, maintenance support system etc.) and hardware (such as aircraft, ground control station, equipment), four aspects and the relationship between the environment and people etc.. Personnel involved in addition to the ground station operators, also including daily and set all people working together, these populations and decision system running on.

\section{THE IMPORTANT SIGNIFICANCE OF INTRODUCING CREW RESOURCE MANAGE MENT CONCEPT OF UAV SYSTEM}

\subsection{To ensure the effective operation of objective requirements without man-machine system}

The UAV system operation characteristics are consistent with the crew resource management goal. The UAV mission, need to ground control, task load and unit coordination, especially large long endurance UAV, need more air to satellite data link provides real-time communication support. If no guarantee the effective operation of man-machine system, each unit of each link must be close coordination, standardized operation, process of operation, any one link or a unit problems among them, will affect the UAV's safety, affect the mission, so for the UAV system, the smooth completion of the task, can guarantee the flight security, the key lies in each unit can run effectively, nodes can smooth coordination, which requires all positions within the unit operator precise operation, close cooperation, solidarity and cooperation. [2]The introduction of crew resource management training in the UAV system, can through the continuous management training, and continuously strengthen the unit group concept, effective collaboration between, foster and strengthen the crew members of each unit and each link, to regulate people's behavior way, failure and threat caused by reducing the human factors in flight, improve the unit communication, management, decision-making and coordination skills, form and keep the safety of flight must attitude, knowledge, skills and other good behavior pattern..

\subsection{The urgent need of scientific construction of unmanned aircraft vehicle department}

UAV aviation authorities how should build, deserves in-depth study of the problem. Must play the maximum efficiency from UAV system starting, actively absorb the advanced management concept, new breakthroughs in ideological understanding, a new improvement in the methods, a new improvement in management efficiency, establish a UAV system mode of operation mechanism and management system, to ensure that the aviation sector can rapidly forming ability, guarantee system of sustainable and efficient operation. Therefore, in the UAV aviation sector is the beginning of construction should be introduced into the crew resource management concept, starting from the human factors and system management, perfect the mechanism, improve measures, truly advanced safety management concept, idea materialized as long-term mechanism and error correction methods, 
and strive to improve the effectiveness and longterm non operating mechanism of man-machine system. To promote the training of safety management system and standardization, refinement, makes the aviation sector construction started in a scientific and reasonable management basis.

\subsection{The rapid formation of an important way of $U A V$ capability and numbering}

A man-machine after launch, ability in some extent depends on the individual pilots, while the UAV system capacity is reflected in the overall capacity of each system control personnel. UAV capability is not only reflected in each member, each unit or each link, the more important thing is finally must manifest whether each link in the unit stable and efficient operation of coordination, so the UAV system in individual attention to technical ability of each system operators at the same time, more attention should be paid to non technical ability to manipulate the whole staff. Including decisionmaking skills, communication skills, leadership skills and stress ability etc.. That is to say, the cultivation of UAV system capacity from simply emphasize personal technology to personal technology and the overall effectiveness of both to play. In this concept under the support, can be achieved through a series of management training, make the unit effective use of all available resources, including hardware, software, environment and human resources, improve the crew communication skills, develop team spirit, rational allocation of tasks, to make the right decision. At the same time through repeated training, the continuous optimization of the link, each process configuration, exert maximum system efficiency purposes.

\section{UAV SYSTEM RESOURCE MANAGEMENT PROBLEM}

\subsection{The thought knows bound}

Crew resource management philosophy only emphasize what is right, and not who are stressed on. On the one hand, new UAV system equipped with a new mechanism, the inevitable need to match with the model, which is in need of the staff work together to create type work, blindly follow the old tradition, is not conducive to the rapid the power of forming UAV system. On the other hand, the "passive" obedience and crew resource management emphasizes "participation", "communication" and "decision" is the core of runs, as the crew resource management training increases the resistance in the promotion of the UAV aviation sector.

\subsection{The lack of training equipment}

Organize the UAV system resource management training needs some training equipment support. According to the characteristics of the UAV system operation and practicability in UAV aviation authorities to carry out the system of resource management is very strong, but now many countries have yet to carry out the relevant business training and professional training organization, although the pilot work related in some big aircraft crew units or more, but only in the stage of exploration, cannot provide effective crew resource management training for other aircraft aviation sector. Therefore, if the development of resource management system in UAV aviation sector, so communication training, situation awareness training, problem solving skills, relationship of obedience training, stress management training and review skills training and a series of training work only by the UAV aerial departments complete yourself, need to simulate machine, psychological evaluation software, such as a series of psychological training field hardware and software support, however these training facilities in the basic level aviation sector, especially the UAV aerial Department of the newly formed basically belongs to the blank, seriously restricted the development of crew resource management training.

\subsection{The theoretical foundation is weak}

At present, the UAV system resource management theory is still in the stage of exploration in the field of aviation, the relevant theory foundation is very weak. The aviation sector there is not theory of specialized research institutions, to understand the related theory of little by little, don't even say can be experts and scholars in-depth study on it. Although some airlines departments to carry out some preliminary research, but the standard setting is accurate, the theoretical research is of scientific and leading, lack of authority identification. [3]A serious lack of theoretical teaching materials is currently the only, but also from the civil aviation and the excessive, aviation mission and aircraft platform be totally different. Because the system materials is not unified, resulting in non training content of manmachine system resource management is not perfect enough, the method is not scientific, quality evaluation of the lack of the corresponding standard basis etc.

\section{SEVERAL SUGGESTIONS FOR UAV SYSTEM RESOURCE MANAGEMENT}

\subsection{To establish a new management concept}

The UAV system resource management is a kind of method, is also a kind of philosophy, we must first get rid of the traditional concept, the new concept of 
firm establish standardization management, operation. One is the ongoing education mobilization. Unity of thinking, summon the will, to promote resource management system and the UAV aerial department culture construction organically; two is to firmly establish the sense of participation. According to the characteristics of the UAV system operation, the staff should develop a "not only on the only true" quality, all to ensure the safe and efficient operation of the UAV system principle, set up the consciousness of cooperation, the courage to stick to the truth, take the initiative to participate in decisions, change "passive obedience" to "active execution"; three is the comprehensive popularization the UAV system resource management. Through the theoretical teaching, lectures, seminars, training and other forms of organization, popularization of knowledge resource management system, so that the majority of the staff understand and grasp the basic connotation, system resource management main content, training methods, standard, behavior index and quality assessment content, form the system of consciousness, good cooperation and situation awareness.

\subsection{Construction meet the training mode}

According to the characteristics of non operation of man-machine system, according to the basic goal of man-machine system resource management training and different training tasks, different stages of training, the trainees to requirements and safety work special needs, determine the corresponding focus of training, training standards and supervision mode, crew resource management model of UAV system built form the standard content standard procedures and methods explicitly cohesion, orderly, focused training. One is the classification training. In accordance with the division of functions, clear all kinds of personnel at different stages, different tasks and different environment in the focus of training, quality standards and supervision, vary from person to person, gang vary targeted training, promote the UAV system standardization, fine operation, to ensure the training quality; two is the piecewise training. According to the basic skills training, qualification training, optimizing resources in three stages, piecewise training for personnel of various kinds, clear stage training content, technical standard and procedure, to achieve a reasonable allocation of resources to maximize the efficiency of the unit, the unit; three is the simulation training. Using the UAV simulator, through simulation, role playing method, make each trainees, the focus is on the crew members to understand the different roles in the process of feeling, strengthen leadership and obedience, flight management and cooperation consciousness, improve coordination, among the members of the crew coordination, the tacit understanding and complementary consciousness.

\subsection{Perfect training mechanism related to}

The UAV system emphasizes the whole unit operation ability, emphasize the position coordination, therefore to UAV system resource management point of view on perfecting training mechanism related, ensure the staff not only to master the professional knowledge and skills of the position, but also to the knowledge related to other professional jobs also have some knowledge, such ability in practical work each post, ensure control staff to stand in the whole system point of view to consider problems, better job. One is from the source. Now, some colleges and universities have opened the UAV professional, specialized personnel training for UAV aviation sector, do not prevent the crew resource management as a compulsory course, began to train crew resource management consciousness from the source, and with the crew resource management idea to set the curriculum, teaching, take the knowledge teaching, role plays, case studies, computer assist training and self-test methods such as questionnaire, in the teaching of UAV knowledge at the same time, also to teach the basic theory of crew resource management, set up the basic concept of crew resource management; two is to maintain continuity. UAV aviation sector is long-term practitioners system resource management, is also the ultimate beneficiaries must overcome difficulties, continue to carry out. The aviation sector to establish correlation system in UAV training and the implementation of important tasks to continue to strengthen inspection and supervision, to UAV system resource management concept with reasonable resources power, system of organization and implementation, timely follow-up inspection unit overall ability, to make the UAV system resource management training is always maintained at a high level; three is to ensure that the time schedule. Because the training is a long-term systems engineering, therefore in the arrangement of the crew members while training may encounter certain difficulties. But no matter how perfect training system, needs to have sufficient training time as a guarantee, no doubt about it.

\section{REFERENCES}

[1]Sun, Y. 2006 .Maintenance resource management and maintenance human factors research. Nanjing: Nanjing University of Aeronautics \& Astronautics.

[2]Chen, Y.Z. 2003. Theory and application of human factors to improve locomotive safety system. Machine technology, 10(3):13

[3]Zeng, X.Y. 2004 .Maintenance resource management (MRM) research. Taiwan: Research on traffic management science of Taipei University. 